\title{
High Mobility Group Box Chromosomal Protein 1 (HMGB1) Is an Antibacterial Factor Produced by the Human Adenoid
}

\author{
CECILIA K. ZETTERSTRÖM, TOMAS BERGMAN, BRITTA RYNNEL-DAGÖÖ, \\ HELENA ERLANDSSON HARRIS, OLLE SÖDER, ULF ANDERSSON, AND HANS G. BOMAN \\ Pediatric Endocrinology Unit [C.K.Z., O.S.], Division of Pediatric Rheumatology [U.A.], Department of \\ Woman and Child Health, Astrid Lindgren Children's Hospital, Karolinska Hospital, Stockholm, Sweden; \\ Department of Medicine, Rheumatology Unit, Karolinska Hospital, Stockholm, Sweden [H.E.H.]; \\ Department of Medical Biochemistry and Biophysics [T.B.], Microbiology and Tumor Biology Center \\ [H.G.B.], Karolinska Institutet, Stockholm, Sweden; Department of Otorhinolaryngology, Huddinge \\ Hospital, Huddinge, Sweden [B.R.-D.]
} \begin{abstract}
ABS
Antibacterial factors were purified from human adenoid
glands by tissue extraction and consecutive steps of reversedphase chromatography and assayed for bactericidal activity against the airway pathogen Moraxella catarrhalis and also Escherichia coli and Bacillus megaterium. One of the most active components isolated from adenoids was identified by $\mathrm{N}$-terminal sequence analysis and mass spectrometry as high mobility group box chromosomal protein 1 (HMGB1). This novel finding was further substantiated by Western blot analysis, demonstrating a protein of expected size reactive with HMGB1 antiserum. Local synthesis was confirmed by reversetranscriptase PCR and in situ hybridization. Adenoid-derived HMGB1 and recombinant HMGB1 revealed comparable anti-
\end{abstract}

Innate immunity refers to the part of the eukaryotic antimicrobial defense machinery that acts and kills invaders within seconds or minutes. The main effector molecules in this system are gene-derived antimicrobial peptides (peptide antibiotics),

Received September 14, 2001; accepted December 18, 2001.

Correspondence: Cecilia K. Zetterström, Department of Woman and Child Health, Pediatric Endocrinology Unit, Karolinska Hospital (Q2:08), SE-171 76 Stockholm, Sweden; e-mail: Cecilia.Zetterstrom@kbh.ki.se

Supported by grants from the Swedish Medical Research Council (Projects 8282, 11412, 03X-10832, 71X-13496, and 03X-3532), the Knut and Alice Wallenberg Foundation, the Carl Trygger Foundation, the Swedish Cancer Society (projects 2677 and 4159), the Swedish Research Council (project K5104-20005891), the Children Cancer Fund, the Foundation Frimurare Barnhuset in Stockholm, H.R.H. Crown Princess Lovisa Society of Pediatric Health Care, the Society for Child Care, the Swedish Society of Medicine, the Foundation of Lennander, the Samariten Foundation, and the Solstickan Foundation.

C.K.Z. previously Cecilia K. Jonsson.

DOI: 10.1023/01.PDR.0000023175.89966.9E bacterial activity at high rate. More than $95 \%$ of bacteria were eradicated within $5 \mathrm{~min}$ by HMGB1 in the cultures. Secretion from the adenoid gland surface was also demonstrated to contain antibacterial activity, mainly mediated by $\alpha$-defensins, but not by HMGB1. We conclude that HMGB1, produced and stored intracellularly in the adenoid gland, contributes to the local antibacterial barrier defense system in the upper respiratory tract. (Pediatr Res 52: 148-154, 2002)

\section{Abbreviations \\ HMGB1, high mobility group box chromosomal protein 1 rHMGB1, recombinant HMGB1}

and this applies both to plants and animals, including invertebrates and vertebrates $(1,2)$. More than 500 antimicrobial peptides have been described to date, of which only 30 have been identified in humans (3). Of these, some are small peptides such as defensins and some are well-characterized larger proteins such as lysozyme, phospholipase $\mathrm{A}_{2}$, and bactericidal permeability increasing protein, contained in neutrophil granules. Another group consists of cleaved fragments of larger proteins such as lactoferrin and cathepsin G.

It was recently reported that nasal secretion contains antimicrobial activity (4) and that the oral mucosa and salivary glands produce $\beta$-defensins (5). The adenoid or pharyngeal tonsil is a part of the mucosa-associated lymphatic tissue responsible for regional immune functions in the upper respiratory tract. The adenoid has been investigated for production 
of immunoglobulins and cytokines (6) but production of antimicrobial peptides has not been studied.

HMGB1, previously known as HMG1, is a 215 -amino acid residue protein that was first isolated as a nuclear factor with high electrophoretic mobility (7). The protein sequence is highly conserved, which means that, apart from two residues in the C-terminal part, the rat/mouse and human HMGB1 sequences are identical. Several studies show that HMGB1 binds with high affinity to specific DNA structures such as bent or kinked DNA (8-12) and it can also interact with Relcontaining transcription factors, e.g. nuclear factor- $\kappa \mathrm{B}$ (13). Rat/mouse HMGB1 is identical to amphoterin, a cell surfaceexpressed protein that has been demonstrated to enhance neurite outgrowth $(14,15)$ and to promote tumor growth through the receptor for advanced glycation end products (16).

HMGB1 has been shown to possess additional important extracellular proinflammatory functions. HMGB1 was discovered to act as a late mediator of endotoxin lethality (17), and increased serum levels of HMGB1 were evident in patients with sepsis (17) and hemorrhagic shock (18). In a recent study, HMGB1 was reported to cause acute lung inflammation (19). HMGB1 has also been demonstrated to act as a potent stimulus of cytokine release by human monocytes (20) and to induce chemotaxis and cytoskeleton reorganization in smooth muscle cells (21).

We here report the novel finding that the human adenoid gland can produce HMGB1, which also acts as an antibacterial factor.

\section{METHODS}

Adenoids and extraction procedure. Adenoids were surgically removed from 10 children below 6 y of age that suffered from airway obstruction. None of the patients had a history of frequent infections such as otitis, tonsillitis, or other airway infections. The frozen adenoids were homogenized and extracted overnight with $60 \%$ aqueous acetonitrile containing $1 \%$ trifluoroacetic acid (22). The extracts were centrifuged at $13,000 \times g$ for $15 \mathrm{~min}$. Supernatants were pooled, lyophilized, and dissolved in water. These aliquots were tested in antibacterial assays and, if active, purified by reversed-phase HPLC.

Before surgical removal of the adenoid, secretion was collected from the surface of the gland. The secretion was diluted $(10 \times$ volume $)$, tested for antibacterial activity, and extracted as described for the glands. All experiments were approved by the local ethical committee at Huddinge University Hospital (registration no. 155/00). Parental consent was obtained in all cases.

Reversed-phase HPLC purification. Reversed-phase chromatography of the supernatant material was performed by gradient elution with acetonitrile using a Vydac $\mathrm{C}_{18}$ column (218TP54, $0.46 \times 25 \mathrm{~cm}$, Grace Vydac, Hesperia, CA, U.S.A.) with a flow rate of $0.8 \mathrm{~mL} / \mathrm{min}$. The HPLC system (Waters, Milford, MA, U.S.A.) used detection at $214 \mathrm{~nm}$. Fractions were collected and lyophilized before further analysis. Solvent A was water with $0.17 \%$ trifluoroacetic acid. Solvent B was acetonitrile with $0.15 \%$ trifluoroacetic acid. All runs were started at $5 \%$ solvent $\mathrm{B}$ isocratic for $10 \mathrm{~min}$. In the first two purification steps, the following gradient with linear segments was used: 5-30\% B during $15 \mathrm{~min}, 30-60 \% \mathrm{~B}$ during $45 \mathrm{~min}$, and $60-90 \%$ B during $5 \mathrm{~min}$. For the third purification step and for analytical HPLC, the gradient was $5-32 \% \mathrm{~B}$ during $10 \mathrm{~min}$, $32-35 \%$ B during $45 \mathrm{~min}$, and $35-90 \%$ B during 2 min.

Bacterial strains and assays for antibacterial activity. The bacterial strains used were Bacillus megaterium (Bm11), Escherichia coli (D21), and Moraxella catarrhalis (Mc) ATCC \# 25238. Antibacterial activity was recorded using both an inhibition zone assay in thin agar plates (23) and as killing rates in liquid Luria-Bertani broth medium (for B. megaterium) (24). The plates (1-mm thickness) contained Luria-Bertani broth medium, $1 \%$ agarose, and about $10^{4}-10^{5} \log$ phase bacteria. Small wells (diameter $3 \mathrm{~mm}$ ) were punched in the assay plates and loaded with samples of $3 \mu \mathrm{L}$. After overnight incubation at $30^{\circ} \mathrm{C}$, the diameters of the growth inhibition zones were measured to estimate the ability of the tested factors to kill bacteria. Lethal concentrations ( $\mathrm{LC}$ in micromolar $\pm \mathrm{SE}$ ), representing the lowest concentration of a substance that will inhibit bacterial growth, were calculated (23). As a method to compare diameters of inhibition zones, we also used cecropin A units. Fixed amounts of cecropin A were applied to assays plates and the inhibition zone diameters were measured. The relation between the zone diameter and the ${ }^{10} \log$ of amount cecropin A applied was linear. One nanogram of applied cecropin A corresponds to one cecropin A unit. This relation curve was used to compare antibacterial activity between our isolated HPLC fractions. For killing rate experiments, bacteria were diluted to a concentration of 1000 cells per $5 \mu \mathrm{L}$ and were incubated at $37^{\circ} \mathrm{C}$ in the presence of HMGB1 purified from adenoid tissue or recombinant rat HMGB1. Aliquots of $10 \mu \mathrm{L}$ were removed at defined time points, diluted to $100 \mu \mathrm{L}$, and immediately spread on Luria-Bertani plates. The plates were incubated at $37^{\circ} \mathrm{C}$ overnight and bacterial colonies were counted.

Structural analysis of HPLC-purified peptides and proteins. Lyophilized chromatographic fractions were dissolved in water. Purity was checked by analytical reversed-phase HPLC. Matrix-assisted laser desorption/ionization (MALDI) mass spectrometry was conducted using a Finnigan MAT Lasermat 2000 instrument. Edman degradation was performed with a Procise cLC or Procise HT instrument (Applied Biosystems, Foster City, CA, U.S.A.). Electrospray mass spectra were recorded using a Q-TOF tandem mass spectrometer (Micromass, Manchester, UK) equipped with a nanospray ion source.

Recombinant HMGB1 protein. $\mathrm{HHMGB} 1$ was purified from E. coli BL21(DE3) pLysS (Novagen, Madison, WI, U.S.A.) transfected with a pCAL-n vector (Stratagene, La Jolla, CA, U.S.A.) containing the rat HMGB1 gene (a kind gift from Dr. K.J. Tracey, North Shore University Hospital, New York, NY, U.S.A.). For exact data on cloning conditions see Ref. 17. Protein expression was induced with isopropyl-D-thiogalactopyranoside, and rHMGB1 was purified using a calmodulin column (Amersham Pharmacia Biotech, Uppsala, Sweden). Purified rHMGB1 was subsequently passed over a polymyxin B column (Pierce Chemical, Rockford, IL, U.S.A.) to reduce the lipopolysaccharide content. The purity of rHMGB1 was verified by SDS-PAGE and Western blot analysis. Protein 
concentration was determined by the Bio-Rad Protein Assay (Bio-Rad Laboratories, Hercules, CA, U.S.A.) according to the manufacturers' protocol.

Western blot analysis and silver staining. HPLC-purified HMGB1 from human adenoids and rHMGB1 were electrophoresed in Tris-Tricine 10-20\% gels (Novex, San Diego, CA, U.S.A.) and transferred to Hybond nitrocellulose membranes (Amersham Pharmacia Biotech). The membranes were blocked with $1 \%$ BSA in Tris-buffered saline containing $0.1 \%$ Tween before incubation with primary rabbit anti-rat HMGB1 antibodies. Peptide antibodies (affinity purified) were generated by Innovagen AB, Lund, Sweden. The peptide used for immunizing rabbits corresponds to amino acid residues $165-183$ of the HMGB1 molecule. Protein-antibody complexes were visualized using a horseradish peroxidase-conjugated donkeyanti-rabbit antibody (1:5000) (Amersham Pharmacia Biotech) and developed using the ECL-system (Amersham Pharmacia Biotech), according to the manufacturer's recommendations. Silver-staining of the gel was performed using Electran Instaview Silver Staining Kit (BDH Laboratory Supplies, Poole, Dorset, U.K.) according to the manufacturer's protocol.

$R N A$ extraction and reverse-transcriptase PCR analysis. Total RNA was extracted from snap-frozen adenoid tissue using an Ultraspec II Kit (Biotecx Laboratories, Houston, TX, U.S.A.) according to the manufacturer's protocol. Total RNA prepared from human monocytes isolated from leukocyte concentrates by density gradient centrifugation were used as a positive control. Primer pairs specific for HMGB1 (forward 5' GGAGGAGCATAAGAAGAAGC, reverse 5' CTGCTTGTCATCTGCAGCAG, annealing temp $52^{\circ} \mathrm{C}$ ) and the housekeeping gene $\beta$-actin (forward 5' CACACTGTGCCCATCTACGA, reverse 5' GTTTCATGGATGCCACAGGA, annealing temp $58^{\circ} \mathrm{C}$ ), the latter used as internal standard, were designed from published cDNA sequences. Superscript cDNA kit (Invitrogen, Carlsbad, CA, U.S.A.) and RNase Inhibitor (Roche Diagnostics Corp., Basel, Switzerland) were used to synthesize cDNA. The end products were used directly for PCR in a PerkinElmer GeneAmp PCR System 2400 (PerkinElmer, Wellesley, MA, U.S.A.) in the presence of 25 pmol primers, 10 pmol deoxyribonucleoside triphosphate, 75 pmol High Fidelity PCR buffer and 1.75 U Expand High Fidelity DNA polymerase (Roche Molecular Biochemicals, Summerville, NJ, U.S.A.). The conditions for amplification were $5 \mathrm{~min}$ at $96^{\circ} \mathrm{C}$, followed by 35 cycles of denaturation for $30 \mathrm{~s}$ at $96^{\circ} \mathrm{C}$, annealing for $30 \mathrm{~s}$ at $52^{\circ} \mathrm{C}$, and extension for $60 \mathrm{~s}$ at $72^{\circ} \mathrm{C}$. Reaction products were analyzed by gel electrophoresis using $2 \%$ agarose containing ethidium bromide ( $15 \mu \mathrm{g}$ to $100 \mathrm{~mL}$ gel).

In situ hybridization histochemistry. A 50-bp oligonucleotide probe for HMGB1 (5'- TCTTCTTCCTCCTCTTCCTCATCCTCTTCATCCTCCTCGTCGTCTTCCTC-3') and a random probe having no similarities to known sequences (GenBank, National Institutes of Health, Bethesda, MD, U.S.A.) were synthesized (DNA Technology, Aarhus, Denmark). The probes were radiolabeled with $\left[{ }^{35} \mathrm{~S}\right]$ deoxyadenosine $5^{\prime}-[\alpha-$ thio]triphosphate at the 3 ' end using terminal deoxynucleotidyl transferase (Amersham Pharmacia Biotech). In situ hybridization histochemistry was performed according to Dagerlind et al. (25). Briefly, sections were hybridized for $18 \mathrm{~h}$ at $42^{\circ} \mathrm{C}$ in humidified boxes and rinsed $5 \times 15 \mathrm{~min}$ in $1 \times \mathrm{SSC}$ at $60^{\circ} \mathrm{C}$. Tissue sections were dehydrated, air-dried, dipped in photographic emulsion (NTB-2, Eastman Kodak, Rochester, NY, U.S.A.), exposed for $3-4 \mathrm{wk}$ at $-20^{\circ} \mathrm{C}$, developed, counterstained with carmalum and mounted (Entellan, Merck, Darmstadt, Germany). Sections were evaluated using bright- and dark-field microscopy (Nikon Eclipse E800, Nikon, Tokyo, Japan).

\section{RESULTS}

Isolation and identification of HMGB1. The lyophilized extracts from adenoid glands were dissolved in water and separated by reversed-phase HPLC. Fractions were collected every minute and lyophilized. After this, fractions were dissolved in water $(10-20 \mu \mathrm{L})$ and analyzed by inhibition zone assay using primarily $B$. megaterium as the test organism.

The most prominent antibacterial activity was detected in two complex peaks eluted after about 40 min elution time (Fig. $1 A)$. Rechromatography of the main peak at 38-39 min gave three to four peaks, with the antibacterial activity detected only in the fraction corresponding to the last of these peaks (data not included). A second rechromatography of this bioactive fraction using a prolonged gradient between $32 \%$ and $35 \%$ acetonitrile gave a single symmetrical peak (Fig. $1 B$ ). The bioactive material resulting from several rounds of three chromatographic steps (Fig. 1B) were pooled and used for studies of antibacterial activity and for protein-chemical identification.

$\mathrm{N}$-terminal sequence analysis of the component corresponding to the active HPLC peak revealed the 15 first amino acid residues to be GKGDPKKPRGKMSSY. This sequence is identical to the N-terminal sequence of human HMGB1, except that the initial methionine residue deduced from cDNA analysis (26) is not present. Preliminary matrix-assisted laser desorption/ionization mass analysis indicated a protein with a size of $24,670 \mathrm{D}$. Using electrospray for a refined mass analysis, a main peak of 24,630 D was detected, which corresponds well to HMGB1 lacking the C-terminal Glu residue, and a peak of 24,758 D, which corresponds to full-length HMGB1 lacking the initial methionine residue, with a theoretical mass of 24,762 D.

The identity of HMGB1 was further confirmed by gel electrophoresis and Western blot analysis. Both recombinant HMGB1 and purified adenoid material exhibited protein bands of the expected size of HMGB1 (Fig. 2, $A$ and $B$ ). The product reacting with polyclonal HMGB1 antibodies was blotted to a polyvinylidene fluoride membrane for Edman degradation. The first 11 residues obtained were GKGDPKKPRGK. Thus, results from $\mathrm{N}$-terminal sequence analysis, mass analysis, and Western blot analysis are consistent with the conclusion that the purified antibacterial adenoid-derived protein is HMGB1 (26).

Reverse-transcriptase(RT)-PCR analysis confirmed a strong expression of HMGB1 mRNA in the adenoid gland (Fig. $3 A$ ) and in situ hybridization histochemistry revealed a distinct expression of HMGB1 mRNA in the germinal centers of adenoids (Fig. 3, $B$ and $C$ ) compared with control sections in 

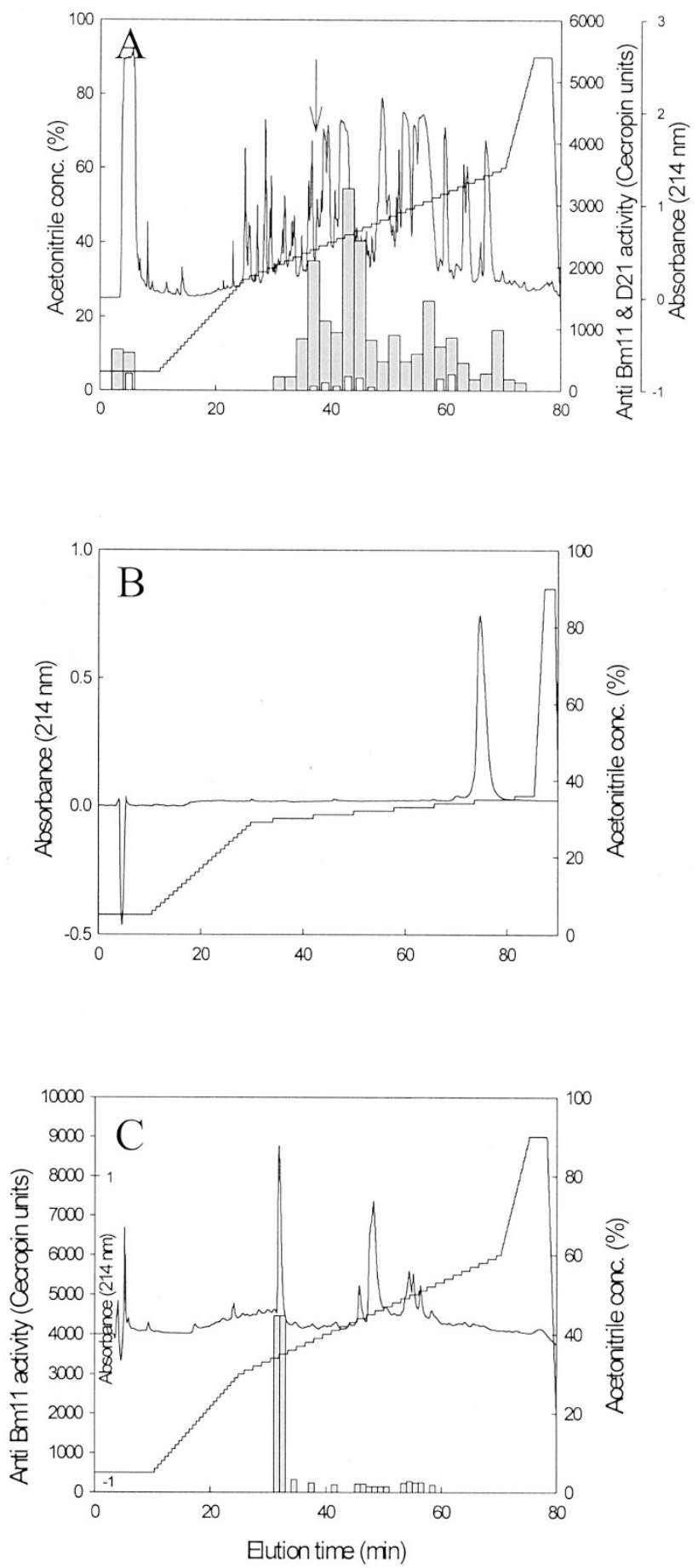

Figure 1. Reversed-phase HPLC purification of HMGB1 and $\alpha$-defensins from the adenoid gland. Chromatograms illustrating $(A)$ the first and $(B)$ the third step of HMGB1 purification from adenoid gland by $\mathrm{C}_{18}$ reversed-phase HPLC. Shaded columns indicate the bactericidal activity against B. megaterium, open columns the killing activity against $E$. coli, expressed as cecropin A units against the respective bacteria. $C$ illustrates a chromatogram of adenoid secretion extracted in the same way as the homogenized adenoid tissue. The main peak eluted at 31-32 min was analyzed by $\mathrm{N}$-terminal sequence analysis and identified as a mixture of three separate $\alpha$-defensins, HNP-1, HNP-2, and HNP-3.

which no signal was evident using a random probe (Fig. 3, $D$ and $E$ ). These results thus indicate a local production of HMGB1 in the adenoid gland tissue.
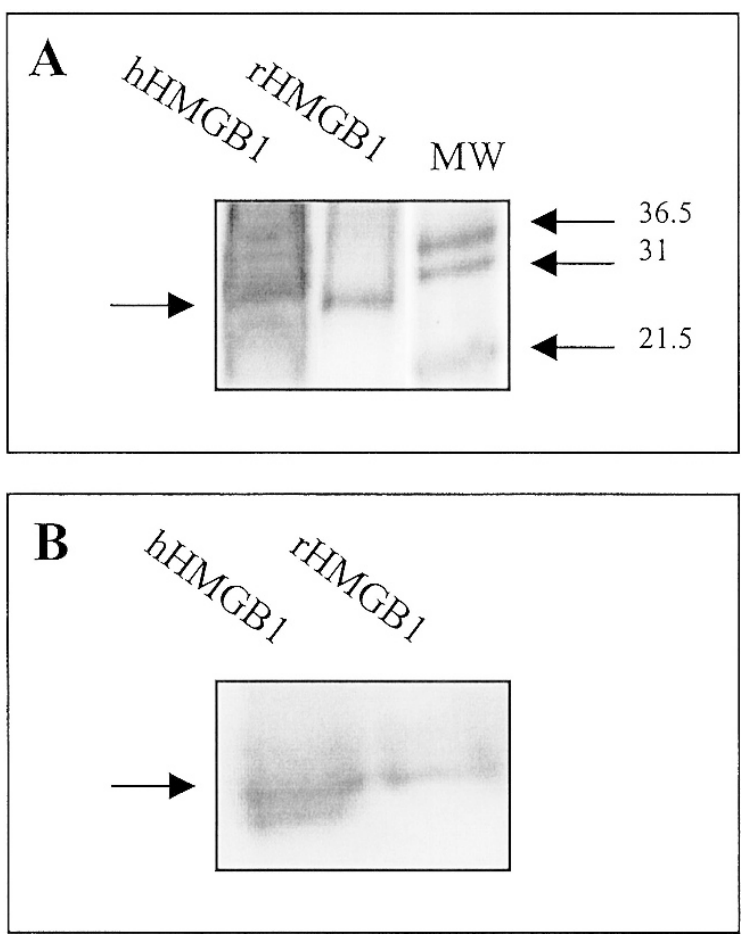

Figure 2. Protein staining $(A)$ and Western blot analysis $(B)$ of rHMGB1 and adenoid-derived HMGB1. $(A)$ Silver staining shows protein bands of an apparent molecular size of slightly below $30 \mathrm{kD}$ for both recombinant and adenoid-derived HMGB1. (B) In Western blot analysis, the immunoreactive bands of hHMGB1 and rHMGB1 both correspond to a molecular mass of approximately $30 \mathrm{kD}$.

Secretion from the surface of the adenoid glands was extracted and HPLC fractionated in the same manner as for the dispersed glandular tissue. Figure $1 C$ depicts the HPLC chromatogram of secretion from the adenoid surface. The pattern differs significantly from that obtained for the intracellular extract (Fig. 1A). The first large peak at 31-32 min revealed significant antibacterial activity against $B$. megaterium, and $\mathrm{N}$-terminal sequence analysis identified three different $\alpha$-defensins, defensin-1 (HNP-1), defensin-2 (HNP-2) and defensin-3 (HNP-3), in the relative proportions 4:4:1. However, we could not detect any HMGB1 in the extracellular surface secretion.

Antibacterial activity. Antibacterial activities against the test organisms B. megaterium (Bm11) and E. coli (D21) and against the airway pathogen $M$. catarrhalis $(\mathrm{Mc})$ are given in Table 1. Adenoid-derived HMGB1 and rHMGB1 were equally efficient in inhibiting bacterial growth, with lethal concentrations below $1 \mu \mathrm{M}$ for $B$. megaterium. The antibacterial effect of HMGB1 was in the same concentration range as for the well-characterized antibacterial peptide cecropin A regarding $B$. megaterium and $M$. catarrhalis, but slightly less efficient versus E. coli (Table 1). Furthermore, rHMGB1 was capable of stimulating cytokine synthesis in cultured human blood monocytes at the same extracellular concentration (20) that was bactericidal (data not shown).

The rate of the bacterial killing corresponded in a dosedependent manner to the amount of added adenoid-derived HMGB1. Killing rates of HMGB1 purified from human ade- 

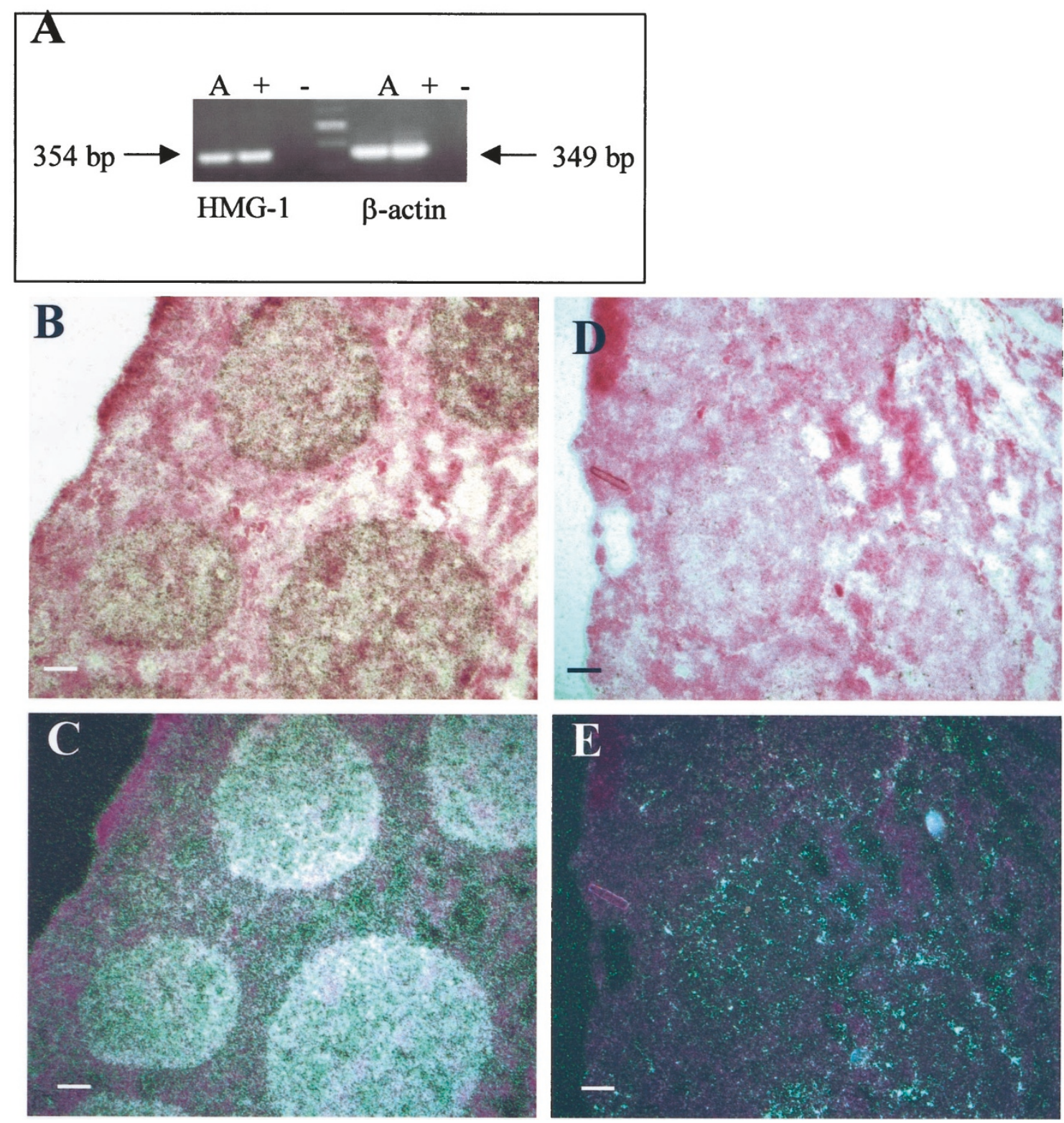

Figure 3. RT-PCR $(A)$ and in situ hybridization histochemistry $(B-E)$ analysis of HMGB1 mRNA expression in human adenoid. HMGB1 mRNA is strongly expressed in the adenoid $(A)$. Human unstimulated monocytes were used as positive control $(+)$ and RT-PCR reaction without addition of mRNA were used as negative control (-). Product size 354 bp. $\beta$-actin were used as reference gene (product size 349 bp). Bright- $(B$ and $D)$ and dark-field $(C$ and $E$ ) photomicrographs of in situ hybridization of HMGB1 mRNA and random probe ( $D$ and $E$ ). A distinct expression of HMGB1 mRNA is localized to the germinal centers of the human adenoid gland $(B$ and $C)$. Use of a random probe show no localized expression $(D$ and $E)$. Scale bars: $100 \mu \mathrm{m}$.

Table 1. Antibacterial activity of $H M G B 1$

\begin{tabular}{lccc}
\hline & \multicolumn{3}{c}{ Strain } \\
\cline { 2 - 4 } Test substance & $\begin{array}{c}\text { B. megaterium } \\
(\mathrm{Bm} 11)\end{array}$ & $\begin{array}{c}\text { M. catarrhalis } \\
\text { (ATCC \#25238) }\end{array}$ & $\begin{array}{c}\text { E. coli } \\
(\mathrm{D} 21)\end{array}$ \\
\hline aHMGB1 & $0.1 \pm 0.0(n=4)$ & $1.2 \pm 0.2(n=3)$ & $2(n=1)$ \\
rHMGB1 & $0.5 \pm 0.0(n=4)$ & $0.3 \pm 0.0(n=2)$ & $3(n=1)$ \\
Cecropin A & $0.6 \pm 0.1(n=3)$ & $0.5 \pm 0.1(n=3)$ & $0.5 \pm 0.1(n=3)$ \\
\hline
\end{tabular}

Antibacterial activities are given as lethal concentrations (LC values in $\mu \mathrm{M})$. $0.4 \mu \mathrm{M}$ recombinant HMGB1 induced tumor necrosis factor- $\alpha$ production in $25 \%$ of cultured human monocytes after $8 \mathrm{~h}$ (data not shown).

noid tissue and recombinant HMGB1 were identical (Fig. 4). Concentrations of $3.5 \mu \mathrm{M}$ for hHMGB1 and rHMGB1 applied to $B$. megaterium killed approximately $80 \%$ of the bacteria within 2 min and $>95 \%$ after 5 min (Fig. 4). If no substance was added, the bacterial density was clearly increased due to normal growth.

\section{DISCUSSION}

The present work demonstrates that the human adenoid tissue produces several antibacterial factors. Extracellular components comprised the well-characterized antibacterial peptides $\alpha$-defensins $1-3$, which were detected in the surface secretion from the adenoid gland. From previous studies, these three defensins are known to appear as a single peak on reversed-phase HPLC (27). The intracellular antibacterial factor detected turned out to be HMGB1. This is, to our knowledge, the first report on an antibacterial activity of HMGB1, 
Survival of Bacillus megaterium

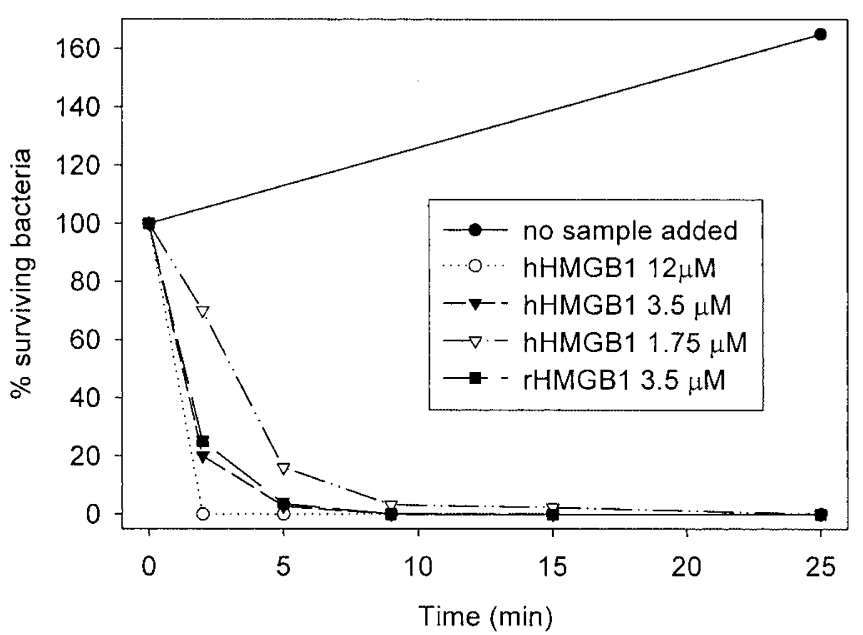

Figure 4. Kinetics of bacterial killing by HMGB1. Rate of killing of $B$. megaterium by human HMGB1 purified from adenoid tissue ( $h H M G B 1)$ and rHMGB1. A dose-dependent killing rate was scored. hHMGB-1 and rHMGB1 displayed a dose-equivalent killing rate. More than $95 \%$ of bacteria were killed within $5 \mathrm{~min}$. When no sample was added, bacterial density was clearly increased.

which now adds to the recently demonstrated proinflammatory role of HMGB1 $(17,20)$. However, other research groups have reported difficulties in expressing rHMGB1 in E. coli, indicating that HMGB1 might be toxic to bacteria (28) and that the choice of vector when expressing rHMGB1 is crucial for the yield of recombinant protein $(10,17,28)$.

The isolation of human HMGB1 from patients without acute infectious symptoms, such as fever, otitis, or airway infections, was unexpected, as recent reports indicate that HMGB1 is a late mediator of the proinflammatory response $(17,29)$. The demonstration of HMGB1 mRNA in the germinal centers of the adenoid confirms that the protein is locally synthesized in the gland. HMGB1 lacks a signal peptide such as the cytokines in the IL-1 and fibroblast growth factor families. This may indicate that HMGB1 protein is normally not designed to leave the cells. Many airway pathogens are encapsulated and are phagocytosed, and thus intracellular antibacterial peptides might be of great importance in eradication of these pathogens. However, it has recently also been clearly demonstrated that extracellular HMGB1 release occurs at inflammatory sites $(17-19)$. It is thus plausible that HMGB1 may enact dual intracellular and extracellular bactericidal activities. The resected adenoid tissue in this study arose from children without clinical signs of ongoing infectious disease and therefore does not allow conclusions about a putative extracellular bactericidal role of HMGB1.

The kinetics of bacterial killing by HMGB1 was rapid, even compared with other well-known antibacterial peptides $(4,30$, 31 ), and HMGB1 eliminated bacteria within a few minutes in a dose-dependent fashion.

The discovery of HMGB1 in the adenoid prompted us to search for HMGB1 in surface secretion from the adenoid gland. No secreted HMGB1 was detectable from noninfected adenoid tissue. However, high HMGB1 concentrations could be expected after necrotic cell damage caused by an infection with strong inflammatory response. The capacity of HMGB1 to bind DNA is interesting inasmuch as it has been determined that other proteins binding DNA or RNA, such as the ribosomal protein $\mathrm{L} 1$ and the histone protein $\mathrm{H} 2 \mathrm{~A}$, can be processed to mediate antibacterial activity (31-33). The mechanisms by which HMGB1 exerts its bactericidal function thus remain to be defined.

We conclude that HMGB1 is a potent antibacterial protein produced and harbored in the adenoid. By delaying or inhibiting bacterial penetration, it may contribute to the barrier defense system in the upper respiratory tract mucosa.

Acknowledgment. The authors thank Associate Professor R.A. Harris for linguistic advice.

\section{REFERENCES}

1. Boman HG 2000 Innate immunity and the normal microflora. Immunol Rev 173:5-16

2. Ganz T, Lehrer RI 1999 Antibiotic peptides from higher eukaryotes: biology and applications. Mol Med Today 5:292-297

3. Synthesis and Bioactivity of Antimicrobial Peptides and Pseudopeptide Inhibitors of HIV Aspartic Protease. Biochimica e Biochimica Applicata per Chimica e Tecnologia Farmaceutiche Web site. Available at: http://www.bbcm.univ.trieste.it/ tossi/. Accessed May 10, 2002

4. Cole AM, Dewan P, Ganz T 1999 Innate antimicrobial activity of nasal secretions. Infect Immun 67:3267-3275

5. Mathews M, Jia HP, Guthmiller JM, Losh G, Graham S, Johnson GK, Tack BF, McCray PB 1999 Production of beta-defensin antimicrobial peptides by the oral mucosa and salivary glands. Infect Immun 67:2740-2745

6. Rynnel-Dagöö B, Lindberg K, Samuleson A, Blomberg S, Forsgren J 1997 The immunology of the host-parasite relationship in the nasopharynx. Ann N Y Acad Sci $830: 32-48$

7. Johns E 1982 The HMG Chromosomal Proteins. Academic Press, London

8. Bianchi ME 1988 Interaction of a protein from rat liver nuclei with cruciform DNA. EMBO J 7:843-849

9. Bianchi ME, Beltrame M, Paonessa G 1989 Specific recognition of cruciform DNA by nuclear protein HMG1. Science 243:1056-1059

10. Bianchi ME 1991 Production of functional rat HMG1 protein in Escherichia coli. Gene 104:271-275

11. Maher JF, Nathans D 1996 Multivalent DNA-binding properties of the HMG-1 proteins. Proc Natl Acad Sci U S A 93:6716-6720

12. Murphy FVT, Sweet RM, Churchill ME 1999 The structure of a chromosomal high mobility group protein-DNA complex reveals sequence-neutral mechanisms important for non-sequence-specific DNA recognition. EMBO J 18:6610-6618

13. Brickman JM, Adam M, Ptashne M 1999 Interactions between an HMG-1 protein and members of the Rel family. Proc Natl Acad Sci U S A 96:10679-10683

14. Rauvala H, Pihlaskari R 1987 Isolation and some characteristics of an adhesive factor of brain that enhances neurite outgrowth in central neurons. J Biol Chem 262:1662516635

15. Merenmies J, Pihlaskari R, Laitinen J, Wartiovaara J, Rauvala H 1991 30-kDa heparin-binding protein of brain (amphoterin) involved in neurite outgrowth. Amino acid sequence and localization in the filopodia of the advancing plasma membrane. J Biol Chem 266:16722-16729

16. Taguchi A, Blood DC, del Toro G, Canet A, Lee DC, Qu W, Tanji N, Lu Y, Lalla E, Fu C, Hofmann MA, Kislinger T, Ingram M, Lu A, Tanaka H, Hori O, Ogawa S, Stern DM, Schmidt AM 2000 Blockade of RAGE-amphoterin signalling suppresses tumour growth and metastases. Nature 405:354-360

17. Wang H, Bloom O, Zhang M, Vishnubhakat J, Ombrellino M, Che J, Frazier A, Yang $\mathrm{H}$, Ivanova S, Borovikova L, Manogue K, Faist E, Abraham E, Andersson J, Andersson U, Molina P, Abumrad N, Sama A, Tracey K 1999 HMG-1 as a late mediator of endotoxin lethality in mice. Science 285:248-251

18. Ombrellino M, Wang H, Ajemian MS, Talhouk A, Scher LA, Friedman SG, Tracey KJ 1999 Increased serum concentrations of high-mobility-group protein 1 in haemorrhagic shock. Lancet 354:1446-1447

19. Abraham E, Arcaroli J, Carmody A, Wang H, Tracey KJ 2000 HMG-1 as a mediator of acute lung inflammation. J Immunol 165:2950-2954

20. Andersson U, Wang H, Palmblad K, Aveberger AC, Bloom O, Erlandsson-Harris H, Janson A, Kokkola R, Zhang M, Yang H, Tracey KJ 2000 High mobility group 1 protein (HMG-1) stimulates proinflammatory cytokine synthesis in human monocytes. J Exp Med 192:565-570

21. Degryse B, Bonaldi T, Scaffidi P, Muller S, Resnati M, Sanvito F, Arrigoni G, Bianchi ME 2001 The high mobility group (HMG) boxes of the nuclear protein HMG1 induce chemotaxis and cytoskeleton reorganization in rat smooth muscle cells. J Cell Biol 152:1197-1206 
22. Moore KS, Bevins CL, Brasseur MM, Tomassini N, Turner K, Eck H, Zasloff M 1991 Antimicrobial peptides in the stomach of Xenopus laevis. J Biol Chem 266:1985119857

23. Hultmark D, Engström A, Andersson K, Steiner H, Bennich H, Boman HG 1983 Insect immunity. Attacins, a family of antibacterial proteins from Hyalophora cecropia. EMBO J 2:571-576

24. Pütsep K, Normark S, Boman HG 1999 The origin of cecropins; implications from synthetic peptides derived from ribosomal protein L1. FEBS Lett 451:249-252

25. Dagerlind A, Friberg K, Bean AJ, Hökfelt T 1992 Sensitive mRNA detection using unfixed tissue: combined radioactive and non-radioactive in situ hybridization histochemistry. Histochemistry 98:39-49

26. Wen L, Huang JK, Johnson BH, Reeck GR 1989 A human placental cDNA clone that encodes nonhistone chromosomal protein HMG-1. Nucleic Acids Res 17:1197-1214

27. Frohm M, Gunne H, Bergman AC, Agerberth B, Bergman T, Boman A, Liden S, Jörnvall H, Boman HG 1996 Biochemical and antibacterial analysis of human wound and blister fluid. Eur J Biochem 237:86-92
28. Lee KB, Brooks DJ, Thomas JO 1998 Selection of a cDNA clone for chicken high-mobility-group 1 (HMG1) protein through its unusually conserved 3'untranslated region, and improved expression of recombinant HMG1 in Escherichia coli. Gene 225:97-105

29. Wang H, Vishnubhakat JM, Bloom O, Zhang M, Ombrellino M, Sama A, Tracey KJ 1999 Proinflammatory cytokines (tumor necrosis factor and interleukin 1) stimulate release of high mobility group protein-1 by pituicytes. Surgery 126:389-392

30. Boman HG, Agerberth B, Boman A 1993 Mechanisms of action on Escherichia coli of cecropin P1 and PR-39, two antibacterial peptides from pig intestine. Infect Immun 61:2978-2984

31. Pütsep K, Branden CI, Boman HG, Normark S 1999 Antibacterial peptide from $H$. pylori. Nature 398:671-672

32. Hirsch JG 1958 Bactericidal action of histone. J Exp Med 108:925-944

33. Park IY, Park CB, Kim MS, Kim SC 1998 Parasin I, an antimicrobial peptide derived from histone H2A in the catfish, Parasilurus asotus. FEBS Lett 437:258-262 